\title{
Hydropolitics and hydrology issues in Hirmand/Helmand international river basin
}

\author{
Azim Shirdeli*
}

Department of Civil Engineering, University of Zanjan, Zanjan, Iran

\section{CH R O N C L E A B S T R A C T}

Article history:

Received October 28, 2013

Received in revised format

25 November 2013

Accepted 29 January 2014

Available online

February 22014

Keywords:

Hirmand river basin

Hydrology

Hydro policy

\begin{abstract}
This paper presents an empirical study to find the steady state of Hirmand/Helmand international basin. Using Markov chain method and by considering seven states including very dry, dry, semi-dry, average, semi-wet, wet and very wet, the proposed study uses historical data over the period 1952-1997 and determines the steady state of the region. The results of the survey indicate that the likelihood of having very dry, dry, semi-dry, average, semi-wet, wet and very wet states are 10.4, 27.6, 9.5, 17.5, 18.5, 11.1 and 5.4 percent, respectively. In other words, there is a chance of $47.5 \%$ for having dry or very dry state, $35 \%$ for having semi and very wet and a likelihood of $17.5 \%$ for having normal condition.
\end{abstract}

\section{Introduction}

Water is the primary source of all developing activities and it is considered as one of the necessary requirements for sustainable development. During the past few years, there have been significant changes on environment, there are limited fresh water resources, the increasing rate of population growth and the hypothetical present and future effects of climate change have created much motivation in governmental level to rethink about conventional approaches on water resources. Therefore, new guidelines have been initiated within the Integrated Water Resources Management framework to help the water sector planners and decision makers. Water has an erratic behavior and in many cases, two or more countries share one common water resource. In such circumstances, many countries try to take advantage of the available water as much as they can, even by ignoring the other stakeholders' rights. Consequently, new concerns such as "national security" arise and conflicts may occur between the riparian countries. Nevertheless, sharing one common resource is an opportunity to bring the riparian countries to the negotiation tables and to involve them in cooperative processes. Hydropolitic investigates the existing conflicts and cooperation processes between the riparian countries in one international basin (Etaat \& Varzesh, 2012).

*Corresponding author.

E-mail addresses: shirdeliazim@gmail.com (A. Shirdeli) 
According to Herdendorf (1982), Himand used to be one of the largest river basin in the world but, the river has lost its position, recently. Fig. 1 shows details of Hirmand region.

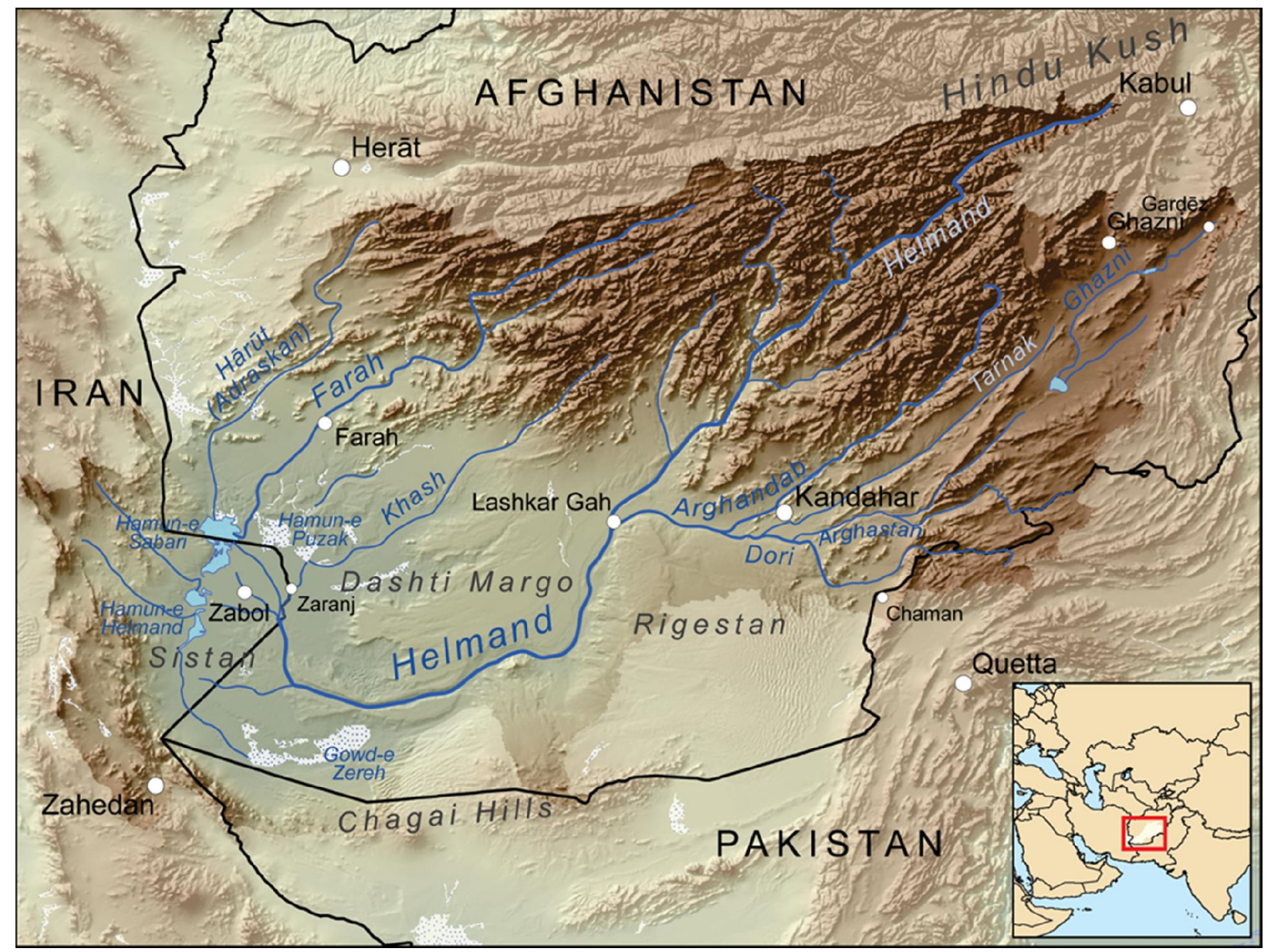

Fig. 1. Hirmand/Helmand River Basin (Source: Wikipedia)

Ettehad (2010) performed a comprehensive study on the case of Hirmand/Helmand River Basin, which includes parts of Iran and Afghanistan. She first tried to provide information from different secondary sources about the general features of the basin. Then, she performed some complementary actions such as field visit and interviews and the process of social learning was triggered to give some insight about what people reflect on the current complex situation.

For years, surface and ground water were primary resources for supplying agricultural, municipal and industrial consumers. Rivers are considered as the supplier of water requirements, such as Hydro powers, water transportation and fresh water. Various kinds of animals and special aquatics spices live in wetlands and groups of migrated birds could spend their winter times in wetlands. Hamoons are considered as transboundary wetlands between Iran and Afghanistan, which receive their water from Hirmand (helmand) River and form a unique freshwater wetland ecosystem of outstanding local, national and international importance. For years, the Iranian Government has designated it as wetland of international importance under the Ramsar Convention in 1975.

The wetlands plays essential role on ecological, economic and cultural value and offer a livelihood to a substantial proportion of the human population in the Sistan basin. Unfortunately, drought has become a serious problem in this region and the vegetation cover has dramatically decreased. The degradation of the ecosystem is of big concern for the authorities as well as the local people, who see their livelihood are jeopardized. The lakes have become completely dry most of the time over the 
period 2001-2005. Fig. 2 shows snowdrift changes in 2006 and 2010. Many people lost their income from reed harvest, fisheries, grazing and bird harvesting and agriculture and they have suffered from severe shortage of water.

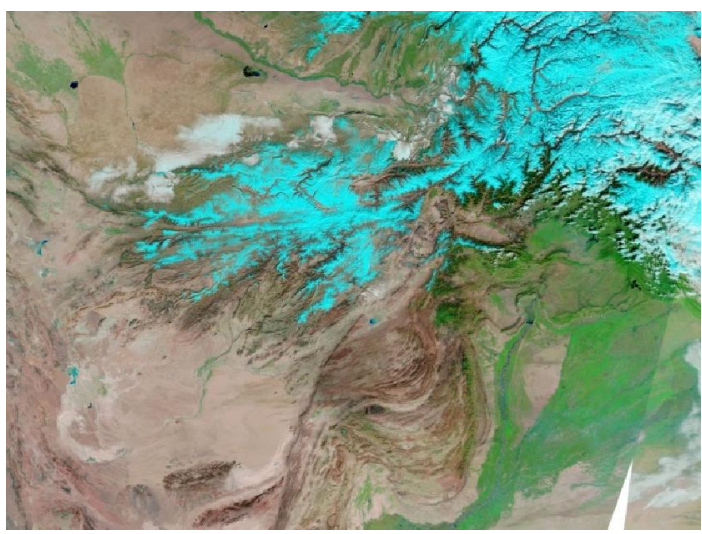

Fig. 1a. Snowdrift in Hirmand region in 2006

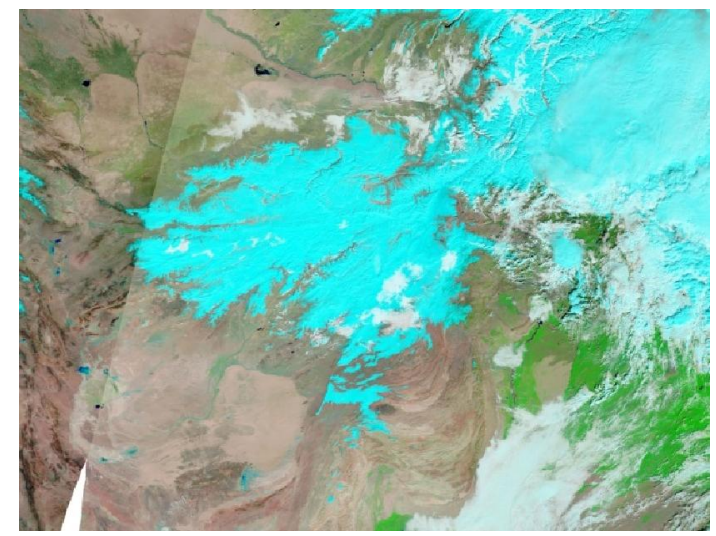

Fig. 1b. Snowdrift in Hirmand region in 2010

Fig. 2. Snowdrift in Hirmand region in 2006 and 2010

There are various reasons for the degradation such as droughts, decreased discharge of the Hirmand River due to increased water use in Afghanistan, over-exploitation of natural resources by the growing local population and the introduction of exotic herbivorous fish, which prevent re-growth of reeds after the droughts of the mid-1980 (Najafi \& Vatanfada, 2011).

Sharifikia (2010) monitored the Hamoun water level changes based on time sires of satellite images to investigate the elements and cause of this hazardous event. The study reported that the Hamoun water level had been changed because of Hamoun sea bead uplifted and height changing. They blamed the roads and bulwark construction as perpendicular line with direction of strong local wind. In addition, the area with length of $14 \mathrm{~km}(492 \mathrm{Km} 2)$ in south Hamoun Pozak was appeared as lake and wetland over the Image related to year 2005 (in Afghanistan side), which was known as dry land in satellite image taken in year 1976.

Najafi and Vatanfada (2011) analyzed the temporal-spatial relationship between the surface water potential and the stability of Hamoon and Godzereh water bodies over the period 1972-2004. Based on the Hirmands' inflows, mainly Parian and Sistan rivers, this analysis was performed using the remote sensing information. They investigated the depths of water, the area of the lakes, and the vegetation of the Sistan Basin and interpreted based on these images using principle components of satellite visual interpretation. They reported that the temporal-spatial stability of Hamoons mainly depends on the Hirmand inflow. Esmaeili and Omrani (2007) measured the relative efficiency of Hammon lake in terms of fishery activities and reported some significant reduction in efficiency.

Chavoshian et al. (2005) performed a comprehensive overview to transboundary and shared water resources management in Iran. They reported Hirmand flow was reduced from 7244 cubic meters in 1990-91 to about one million cubic meters in 2001-2002. Therefore, over 70\% of the people in Iran migrated to other provinces. Burger (2005) performed a study on calibration of a participation runoff model for Hirmand river in Afghanistan and Iran using remote sensing data. The study on snow cover with snow cover detected on satellite images indicated the snow was overestimated. Therefore, the melting constant in this part of the catchment was lowered from 4 to $3 \mathrm{~mm} /$ degrees Celsius per day.

Satellite images are indicators of the amount of water stored in any reservoir such as Afghan reservoirs. In addition, a survey on the region has disclosed good information about water discharged from the region. The refilling of any reservoir is an indicator of the amount of existing water in the 
region. The Farah river is considered as the second important river in the Hirmand basin region and it is the primary source of Hamon-e-Saberi and since the government of Afghanistan plans to build a reservoir in the Farah Basin, we may expect a substantial decrease in water inflow in Hamoun-eSaberi region.

Desertification is considered as land degradation and loss of biological productivity in arid, semi-arid and dry sub-humid areas because of climatic variations and destructive human activities. The vegetative mass is also considered as the major biological production of dry lands. Therefore, one can consider the deterioration of plant cover as the primary indicator of desertification process. Sistan plain is an arid region that suffers from severe kinds of desertification and land degradation. To study the trend of vegetation cover changes that was occurred during 1990-2006 periods Shafie et al. (2011) performed a two-year study in the region using TM and ETM+ images plus with RS software. All needed processes were executed including geometric and radiometric corrections, mosaicing, clipping, PCA and Tasseled cap. In this study, field sampling was executed in 26 sites with 9 plots in each site and to detect the best vegetation index (VI), they assessed 83 VIs, among them WDVI, TSAVI2, MSAVI1 and NDVIab proved to be the best for separating and discriminating the plant cover on the images with correlation coefficients of $0.89,0.86,0.84$ and 0.70 , respectively. They also classified the images in two categories: vegetation and non-vegetation. Kappa coefficients of resulted classification maps for 4 selected indices calculated using confusion matrix, implying that WDVI map was the most accurate map. Finally, change detection map was achieved by subtracting images, demonstrating that $11.37 \%$ (95288.9 ha) of the study area experienced changes in vegetation cover over the period 1990-2006.

Palau, R.G. (2013) performed an investigation on the global trends in water security and the threats to regional stability posed by the transboundary water resources. He also explaned salient details in the particular case of Afghanistan's transboundary water resources, reviewed disputes over the four main international basins Afghanistan shares with its neighbouring countries, and introduces a framework to properly manage water resources.

Kwadijk and Diermanse (2006) performed a survey on Sistan province where the purpose of the system was to provide the water authorities in Zabol with information on the expected water supply to the Sistan Plain. The results of the long-range model seemed to be necessary to take timely decisions on the use and distribution of the water in the coming period.

\section{The proposed study}

This paper presents an empirical study to find the steady state of Hirmand/Helmand international basin. Using Markov chain method (Monotonicity, 1979; Neal, 2000) and by considering seven states including very dry, dry, semi-dry, average, semi-wet, wet and very wet, the proposed study uses historical data over the period 1952-1997 and determines the steady state of the region. Table 1 shows characteristics of each region in terms of flow.

Table 1

The summary of input flow in terms of cubic meters/second

\begin{tabular}{cccccccc} 
State & Very Dry & Dry & Semi-dry & Average & Semi-wet & Wet & Very wet \\
\hline Range & $17.5-60$ & $75-116$ & $126-130$ & $160-183$ & $198-240$ & $256-294$ & $420-456$ \\
\hline
\end{tabular}

\section{The results}

In this section, we present details of the implementation of Markov process to determine the steady state of the region. Table 2 shows details of transfer matrix associated with seven different states. 
Table 2

Transfer matrix

\begin{tabular}{cccccccc}
\hline State & Very Dry & Dry & Semi-dry & Average & Semi-wet & Wet & Very wet \\
\hline Very Dry & 0.25 & 0.50 & 0 & 0.25 & 0 & 0 & 0 \\
Dry & 0.1818 & 0.2727 & 0.0909 & 0.1818 & 0.1818 & 0.0909 & 0 \\
Semi-dry & 0 & 0.25 & 0 & 0.25 & 0.25 & 0.25 & 0 \\
Average & 0 & 0.25 & 0.25 & 0.125 & 0.125 & 0.125 & 0 \\
Semi-wet & 0 & 0.1428 & 0.1428 & 0.2825 & 0.1428 & 0.1428 & 0.1428 \\
Wet & 0.25 & 0.50 & 0 & 0 & 0 & 0 & 0.25 \\
Very wet & 0 & 0 & 0 & 0 & 0.75 & 0.25 & 0 \\
\hline
\end{tabular}

We have used Markov equations and the results of a $7 \times 7$ model yields the following results.

Table 3

The results of steady state

\begin{tabular}{cccccccc}
\hline State & Very Dry & Dry & Semi-dry & Average & Semi-wet & Wet & Very wet \\
\hline Probability & 10.4 & 27.6 & 9.5 & 17.5 & 18.5 & 11.1 & 5.4 \\
\hline
\end{tabular}

The results of the survey indicate that the likelihood of having very dry, dry, semi-dry, average, semiwet, wet and very wet states are 10.4, 27.6, 9.5, 17.5, 18.5, 11.1 and 5.4 percent, respectively. In other words, there is a chance of $47.5 \%$ for having dry or very dry state, $35 \%$ for having semi and very wet and a likelihood of $17.5 \%$ for having normal condition.

\section{Conclusion}

We have presented an empirical investigation to determine the steady state of Hirmand basin river. The study has detected that the region will more likely face with various unpleasant drought incidents during the next few decades. This means that there is a need to take necessary action to protect the people who live in the region against possible problems. In fact, the region is presently threatened by relatively high ratio of unemployment and many people could migrate to other regions in case consequences of drought continuous.

\section{Acknowledgement}

The author would like to thank the anonymous referees for constructive comments, which improved the quality of the presentation of this paper.

\section{References}

Burger, A.S. (2005). Calibration of a participation runoff model for Hirmand river in Afghanistan and Iran using remote sensing data. Master's Thesis in Faculty of Civil Engineering and Geosciences, Department of Water Management, Section Water Resources, Delft University of Technology.

Chavoshian, S. A., Takeuchi, K., \& Funada, S. (2005). An overview to transboundary and shared water resources management in Iran, technical challenges and solutions. The Role of Water Sciences in Transboundary River Basin Management, Proc. Thailand, 189-195.

Etaat, J., \& Varzesh, I. (2012). Hydropolitic of Hirmand: Reasons, Results and Outcomes. Human Geography, (80), 27.

Ettehad, E. (2010). Hydropolitics in Hirmand/Helmand international river basin. NM006 Integrated Water Resource Management - Master's Programme 120 HEC.

Esmaeili, A., \& Omrani, M. (2007). Efficiency analysis of fishery in Hamoon lake: Using DEA approach. Journal of Applied Sciences, 7(19), 2856-2860.

Khosravi, M. (2010). Temporal and spatial analysis of the stability of the Hamoon lakes. Iran-Water Resources Research, 6(3), 68-79. 
Kwadijk, J., \& Diermanse, F. (2006). Integrated water resources management for the Sistan closed inland delta, Iran: Forecasting the flow from Afghanistan. Water Research Institute, WL delf hydraulics.

Herdendorf, C. E. (1982). Large lakes of the world. Journal of Great Lakes Research, 8(3), 379-412.

Monotonicity, S. (1979). Markov chain models - rarity and exponentiality. Applied Mathematical Sciences, 28.

Najafi, A., \& Vatanfada, J. (2011). Environmental challenges in trans-boundary waters, Case Study: Hamoon Hirmand Wetland (Iran and Afghanistan). International Journal of Water Resources and Arid Environments, 1(1), 16-24.

Neal, R. M. (2000). Markov chain sampling methods for Dirichlet process mixture models. Journal of computational and graphical statistics, 9(2), 249-265.

Palau, R.G. (2013). Water security: Afghanistan transboundary water resources in regional context. Transboundary, 1-15.

Sharifikia, M. (2010). Monitoring water level change detection of Hamoun Lake based on time series of satellite images. The $5^{\text {th }}$ Annual International Power Electronics, Drive Systems and Technologies Conference, February 5-6, 2004, Tehran, Iran.

Shafie, H., Hosseini, S. M., \& Amiri, I. (2011). Assessment of desertification trends in Sistan Plain, Iran using Rs and GIS. International Journal of Forest, Soil and Erosion, 2(2), 97-100. 